\title{
Glycerophospholipid Profiles of Bats with White-Nose Syndrome
}

\author{
Evan L. Pannkuk ${ }^{1, *}$ \\ Liam P. McGuire ${ }^{2, \dagger}$ \\ Lisa Warnecke $e^{2 \ddagger}$ \\ James M. Turner ${ }^{2 \ddagger}$ \\ Craig K. R. Willis ${ }^{2}$ \\ Thomas S. Risch ${ }^{3}$ \\ ${ }^{1}$ Graduate Program of Environmental Science, Arkansas State \\ University, PO Box 847, State University, Arkansas 72467; \\ ${ }^{2}$ Department of Biology, University of Winnipeg, 515 Portage \\ Avenue, Winnipeg, Manitoba R3B 2E9, Canada; ${ }^{3}$ Department \\ of Biological Sciences, Arkansas State University, PO Box 599, \\ State University, Arkansas 72467
}

Accepted 3/7/2015; Electronically Published 5/7/2015

Online enhancements: supplementary table and figures.

\begin{abstract}
Pseudogymnoascus destructans is an ascomycetous fungus responsible for the disease dubbed white-nose syndrome (WNS) and massive mortalities of cave-dwelling bats. The fungus infects bat epidermal tissue, causing damage to integumentary cells and pilosebaceous units. Differences in epidermal lipid composition caused by $P$. destructans infection could have drastic consequences for a variety of physiological functions, including innate immune efficiency and water retention. While bat surface lipid and stratum corneum lipid composition have been described, the differences in epidermal lipid content between healthy tissue and $P$. destructans-infected tissue have not been documented. In this study, we analyzed the effect of wing damage from $P$. destructans infection on the epidermal polar lipid composition (glycerophospholipids [GPs] and sphingomyelin) of little brown bats (Myotis lucifugus). We hypothesized that infection would lead to lower levels of total lipid or higher oxidized lipid product proportions. Polar lipids from three damaged and three healthy wing samples were profiled by electrospray ionization tandem mass spectrometry. We found lower
\end{abstract}

${ }^{*}$ Corresponding author. Present address: Department of Biochemistry and Molecular and Cellular Biology, Georgetown University, 3970 Reservoir Road NW, Washington, DC 20057; e-mail: elp44@georgetown.edu.

$\dagger$ Present address: Department of Biological Sciences, Box 43131, Texas Tech University, Lubbock, Texas 79409-3131.

$\ddagger$ Present address: Department of Animal Ecology and Conservation, Biocentre Grindel, University Hamburg, Martin-Luther-King-Platz 3, 20146 Hamburg, Germany.

Physiological and Biochemical Zoology 88(4):425-432. 2015. (C) 2015 by The University of Chicago. All rights reserved. 1522-2152/2015/8804-4151\$15.00. DOI: $10.1086 / 681931$ total broad lipid levels in damaged tissue, specifically etherlinked phospholipids, lysophospholipids, phosphatidylcholine, and phosphatidylethanolamine. Thirteen individual GP species from four broad GP classes were present in higher amounts in healthy tissue. Six unsaturated GP species were absent in damaged tissue. Our results confirm that $P$. destructans infection leads to altered lipid profiles. Clinical signs of WNS may include lower lipid levels and lower proportions of unsaturated lipids due to cellular and glandular damage.

Keywords: white-nose syndrome, glycerophospholipid, bat integument, wing damage, electrospray ionization, mass spectrometry.

\section{Introduction}

White-nose syndrome (WNS) is a fungal disease that has drastically altered bat species composition in eastern North America (Blehert et al. 2009; Frick et al. 2010; Lorch et al. 2011). The causative agent, Pseudogymnoascus destructans, germinates and grows on bat integument, penetrates wing tissue, and causes necrotic cupping erosions (Meteyer et al. 2009). Changes in bat integumentary protein/lipid matrix are altered during fungal infection by a complex interaction between secreted fungal enzymes (e.g., proteases and lipases) and host tissue (Brock 2009). Enzymes secreted by other fungal pathogens are known virulence factors, as they absorb nutrients from host tissue and allow penetration of integumentary biopolymers (Yike 2011). Fungal infection of wing tissue in hibernating bats is particularly problematic, as wings play important roles in homeostasis (Cryan et al. 2010). Wing surface lipids function in protection from pathogenic microbes, toxic agents, UV radiation, desiccation, and mechanical insult (Elias 2006). Cellular damage and altered lipid compositions may play a role in observed clinical signs of WNS such as dehydration (Willis et al. 2011) and electrolyte imbalances (Cryan et al. 2013; Warnecke et al. 2013).

Glycerophospholipids (GPs) are major building blocks of cellular membranes and function in cellular signaling and membrane trafficking (Silvius 1993; fig. 1). Major classes include phosphatidylcholines (PCs), phosphatidylethanolamines (PEs), phosphatidylinositols (PIs), phosphatidylserines (PSs), phosphatidic acids (PAs), and phosphatidylglycerols (PGs; Fahy et al. 2005, 2009). GPs with one fatty acyl (FA) per molecule are lysoglycerophospholipids (monoradylglycerophospholipids), such as lysophosphatidylcholines (LPCs) or lysophosphatidylethanolamines (LPEs). Ether-linked GPs (eGPs) with a vinyl ether linkage present at the $s n-1$ position (the most common animal eGP structure) are termed plasmalogens (Nagan and Zoeller 2001). 


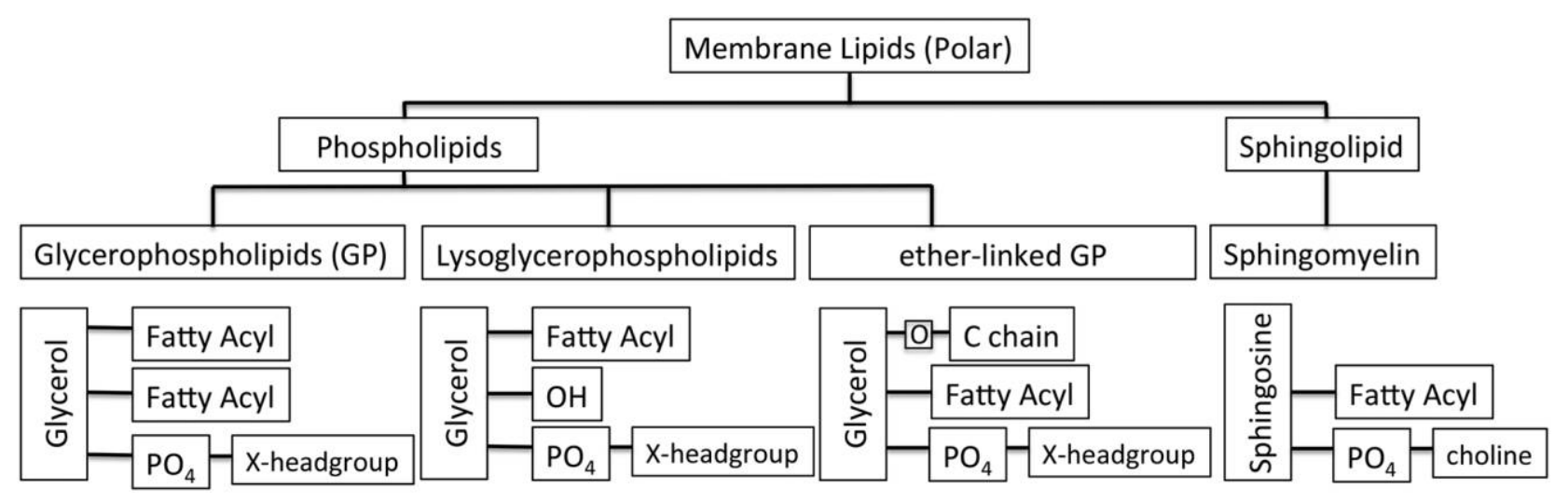

Figure 1. Structure of broad membrane polar lipid classes.

Sphingolipids (SPs) function differently from GPs and serve as base material for complex lipid species such as sphingomyelin (SM; i.e., ceramide phosphorycholine), ceramides, cerebrosides, gangliosides, and others (Fahy et al. 2005). Due to the variety of broad SP classes, these molecules have a wide functional range in mammalian tissues. Gangliosides and SM are primarily structural components of cellular membranes (Brown and London 1998), while ceramides are important second messengers in signal transduction, such as apoptosis (Hannun and Obeid 2011). GPs and SPs may function in host-pathogen interactions in myriad ways (review in van der Meer-Janssen et al. 2010), such as supplying choline or inositol from GP head groups (Comerci et al. 2006; Reynolds 2009; Aktas et al. 2010) to suppressing apoptosis by SP signaling (Greenberg and Yao 2004).

Detailed analyses of polar lipids, including GP, in bats are rare, and the tissues and species sampled are diverse. In mice and bats, lipid chemical composition may vary among tissues, age groups, and species (Jain et al. 2014; Pannkuk et al. 2014b). Previous studies have documented SM composition in Rousettus aegyptiacus (van der Westhuyzen and Cantrill 1983) and GP composition in Nyctophilus geoffroyi (Slocombe et al. 2000), Chalinolobus gouldii (Lang et al. 2005), five Pteropus spp. (Melville et al. 2012), Lasiurus cinereus (McGuire et al. 2013), and Lasiurus borealis (Pannkuk et al. 2014c) in tissues ranging from pulmonary surfactants to flight muscle and fur. In addition to variation in tissues and species, only two studies have used electrospray ionization (ESI) tandem mass spectrometry (MS), quickly identifying GPs to a molecular species level (Lang et al. 2005; Pannkuk et al. 2014c). ESI tandem MS is the most common method for polar lipid analysis, while atmosphericpressure chemical ionization is more suitable for nonpolar lipids, such as waxes (Cajka and Fiehn 2014). Given the important biological roles that GPs play in epidermal function and water retention, coupled with the lack of molecular GP catalogs for Chiroptera, detailed description of the GP profiles of wing tissue in species affected by WNS could provide valuable insight into disease processes and functional consequences of infection.

In a disease context, presence/absence of specific lipid ratios or molecules can be a powerful tool for diagnosis and deter- mining disease mechanisms (i.e., lipid biomarkers). In human medicine, lipid biomarkers may be used to predict disease onset, as in Alzheimer's disease (Mapstone et al. 2014), and to determine disease mechanisms facilitating drug discovery (Vihervaara et al. 2014). Given the availability of alternative indicators of WNS (e.g., quantitative polymerase chain reaction analysis for presence of $P$. destructans [Muller et al. 2013], ultraviolet fluorescence [Turner et al. 2014]), the importance of lipid biomarkers is less a diagnostic motive but could be valuable for determining mechanisms facilitating host/pathogen interactions and quantifying inter- and intraspecific WNS severity. Lipid biomarkers may provide a method to determine how $P$. destructans interacts with host tissue, may differentiate infection stages, and may ultimately confirm pathophysiological mechanisms underlying disease (Warnecke et al. 2013).

Our objectives were (1) to describe wing epidermal lipid profiles in a bat species affected by WNS; (2) to document changes in epidermal lipid profiles caused by $P$. destructans infection; and (3) to identify candidate lipid biomarkers that may provide insight into disease status, processes, or severity. We used ESI tandem MS to profile the polar lipid fraction (GP and SM) from wing tissue of Myotis lucifugus with and without wing damage caused by $P$. destructans. We predicted that infection would lead to lower levels of total lipid or higher oxidized lipid product proportions and that these changes would be concentrated at the sites of wing damage.

\section{Material and Methods}

\section{Bats and Captivity}

Wing tissue analyzed for this study was excised from bats in a separate captive hibernation study (J. M. Turner, L. Warnecke, and C. K. R. Willis, unpublished manuscript; fig. 2), which followed methods described by Warnecke et al. (2012). Bats were captured during hibernation and did not eat during captivity. Therefore, their lipid profiles reflect natural fall diets before hibernation. Hibernating Myotis lucifugus were collected from a WNS-negative cave in central Manitoba, Canada, and transported directly to the Western College of Veterinary Medicine 

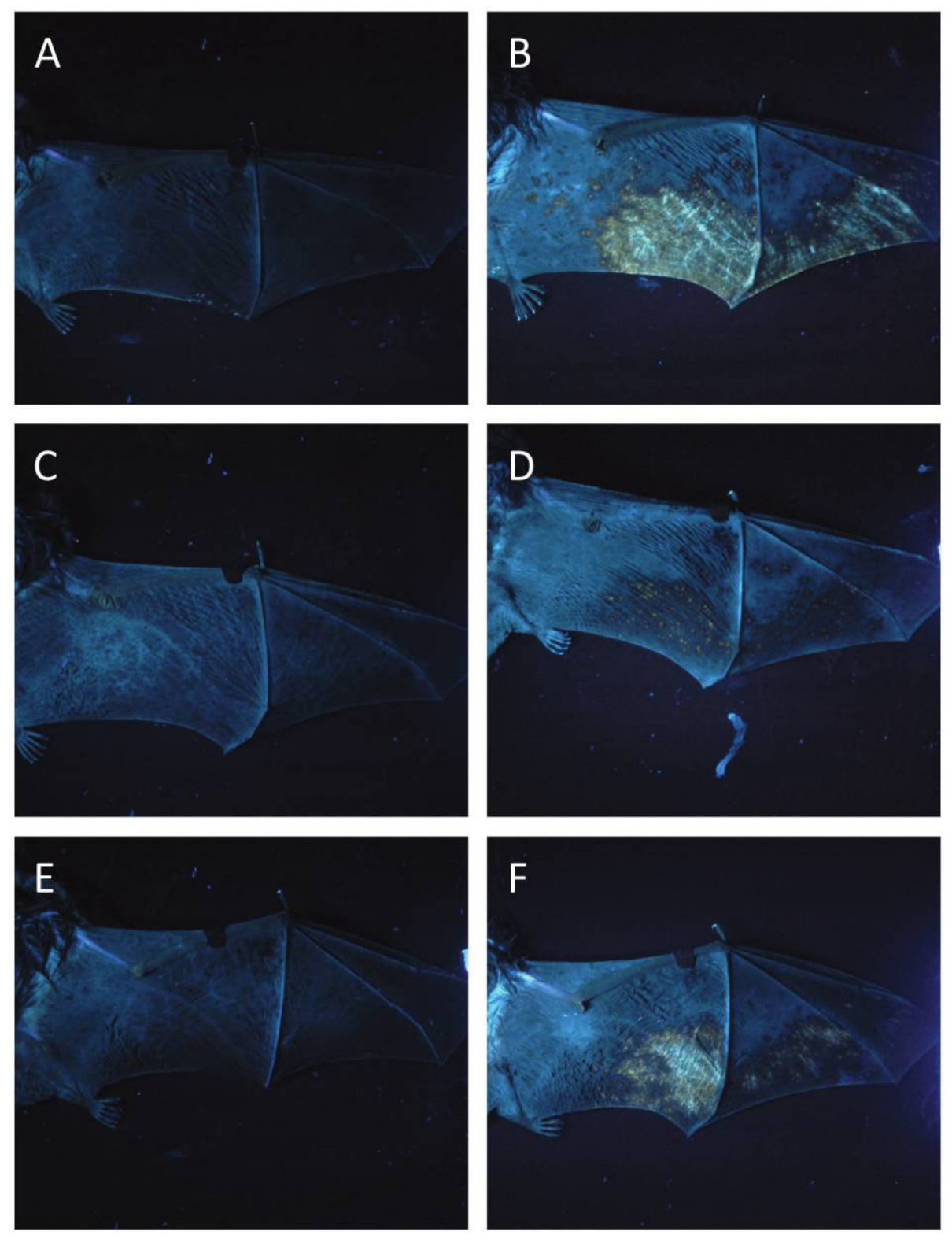

Figure 2. Long-wave ultraviolet (UV) fluorescence of wing lesions caused by Pseudogymnoascus destructans infection ( $A, C$, E, sham-inoculated wings; $B, D, F$, laboratory-inoculated wings). Orange fluorescence is characteristic of white-nose syndrome lesions. Tissue samples came from the plagiopatagium, the region of the wing from the body to the fifth digit.

at the University of Saskatchewan, Saskatoon (Manitoba Conservation permit WB13148, University of Saskatchewan Committee on Animal Care and Supply protocol 20100120). Upon arrival, bats were randomly assigned to treatment or control groups. Treatment bats were inoculated with approximately 500,000 Pseudogymnoascus destructans conidia suspended in PBS-Tween-20 as previously described (Warnecke et al. 2012). Control bats were sham inoculated with the same volume of solution lacking $P$. destructans conidia. Bats were placed in cages in temperature- and humidity-controlled chambers $\left(7^{\circ} \mathrm{C}\right.$, $90 \%$ relative humidity) for hibernation. Hibernating bats were monitored with motion-triggered infrared video (model HT650IRVFHQ, Speco Technologies, Amityville, NY), had ad lib. access to water, and were not disturbed other than to remove individuals showing signs of morbidity. After 105-107 d, the bats were removed from the hibernation cages and euthanized by decapitation under isoflurane anesthesia. The plagiopatagium (fig. 2) from each bat was removed, placed in Eppendorf tubes, and stored at $-20^{\circ} \mathrm{C}$ until shipping for analysis.

\section{Lipid Extraction and Analysis}

Samples were placed on dry ice and shipped overnight to the Arkansas Biosciences Institute, Jonesboro. Healthy (control bats; fig. $2 A, 2 C, 2 E$ ) or necrotic (inoculated bats; fig. $2 B, 2 D$, $2 F$ was used for targeting necrotic tissue) tissue sections were 
Table 1: Comparison of broad glycerophospholipid class (nmol amount/mg dry tissue weight) between healthy (sham-inoculated control bats) and necrotic (Pseudogymnoascus destructans-inoculated bats) Myotis lucifugus wing tissue

\begin{tabular}{lcccr}
\hline Broad class & Healthy & Damaged & $t$ & $P$ \\
\hline ePC & $.79 \pm .05$ & $.52 \pm .06$ & 3.50 & .02 \\
ePE & $. \mathbf{1 4} \pm .01$ & $.06 \pm .01$ & 6.03 & $<.01$ \\
ePS & $.09 \pm .01$ & $.07 \pm .01$ & 1.35 & .25 \\
LPC & $.45 \pm .04$ & $.12 \pm .01$ & 8.58 & $<.01$ \\
LPE & $\mathbf{. 1 1} \pm<.01$ & $.04 \pm .01$ & 9.37 & $<.01$ \\
PA & $.02 \pm .01$ & $.01 \pm .01$ & .54 & .62 \\
PC & $\mathbf{1 . 5 3} \pm .14$ & $.78 \pm .07$ & 4.77 & .01 \\
PE & $.52 \pm .06$ & $.24 \pm .03$ & 4.53 & .01 \\
PG & $.13 \pm .03$ & $.05 \pm<.01$ & 2.76 & .12 \\
PI & $.09 \pm .03$ & $.02 \pm .01$ & 2.09 & .10 \\
PS & $1.03 \pm .08$ & $.74 \pm .10$ & 2.17 & .10 \\
SM & $3.91 \pm .44$ & $3.76 \pm .18$ & .31 & .77 \\
\hline
\end{tabular}

Note. All data are means \pm SE. Significantly higher means are shown in bold. $n=3$ per treatment. ePC, ether-linked phosphatidylcholine; ePE, etherlinked phosphatidylethanolamine; ePS, ether-linked phosphatidylserine; LPC, lysophosphatidylcholine; LPE, lysophosphatidylethanolamine; PA, phosphatidic acid; PC, phosphatidylcholine; PE, phosphatidylethanolamine; PG, phosphatidylglycerol; PI, phosphatidylinositol; PS, phosphatidylserine; SM, sphingomyelin.

excised and total lipid was extracted with chloroform: methanol as previously described (Pannkuk et al. 2013). Solvent was evaporated under a stream of $\mathrm{N}_{2}$ and stored at $-20^{\circ} \mathrm{C}$. All storage solvents contained $0.05 \%$ butylated hydroxytoluene (Law et al. 1995) and were of high-performance liquid chromatography grade (Fisher Scientific).

Lipid extract samples were shipped overnight to Kansas Lipidomics Research Center (Pannkuk et al. 2014c). GP and SM profiling was performed with ESI tandem MS by determining the mass-to-charge ratio $(\mathrm{m} / \mathrm{z})$ of intact ions and the $\mathrm{m} / \mathrm{z}$ of head group fragments (see Wanjie et al. 2005). Lipid amounts are reported as nanomole per milligram dry tissue normalized to a $1.0-\mathrm{nmol}$ internal standard.

\section{Statistical Analysis}

Total lipid (nmol amount/mg dry tissue weight) for broad GP classes (i.e., cumulative amount for all compounds within each broad group) was compared between healthy and necrotic tissue with a Welch's $t$-test (SAS 9.2; SAS, Cary, NC). For individual lipid species, data were centered/scaled and compared with a principle component analysis (PCA) with the software R (ver. 2.9.2). To determine potential GP biomarkers, ions were log transformed and normalized with a Gaussian transformation, and complete-presence ions (defined as present in at least five of six samples) were compared with a Welch's $t$-test (MetaboLyzer 10.0; Mak et al. 2014).

\section{Results}

For both healthy and necrotic tissue, SM was the dominant lipid class with lower amounts of PS, PE, PC, LPC, and ether- linked PC (ePC; table 1; figs. S1, S2; figs. S1-S10 available online). Individual classes that accounted for less than $2 \%$ of total lipid content (LPE, ether-linked PE [ePE], PI, PA, and PG) were excluded from further analysis. The SM fraction comprised a higher percentage of the total polar lipid fraction in damaged tissue (59\%) than healthy tissue $(44 \%)$ due to lower total GP levels $(t=10.67, P=0.002)$. Although there was a nonsignificant trend $(t=2.12, P=0.08)$ for lower mean total GP in necrotic $(2.65 \pm 0.28)$ versus healthy $(4.90 \pm 0.47)$ tissue, the effect size was large (Cohen's $d=2.45$; Nuzzo 2014). Within individual GP classes, mean total ePE, LPC, PC, and PE were lower in damaged tissue than healthy tissue (table 1).

A total of 146 complete-presence ions were detected (table S1, available online; figs. S3-S8). PCA clearly differentiated damaged versus healthy Myotis lucifugus wing tissue (fig. 3; see also figs. S9, S10), where principle component 1 accounted for $66.5 \%$ of the variation and principle component 2 accounted for $14.9 \%$ of the variation. Of these 146 complete-presence ions, two PS, five PE, four PC, and three LPC ions were present in different amounts in damaged and healthy tissue (table 2). All were present in lower amounts in damaged tissue except $\mathrm{PE}(40: 6)$, which was slightly more abundant than healthy tissue. Six unsaturated GPs were not detected in damaged tissue but were present in healthy tissue (table 2).

\section{Discussion}

This is the first study to document bat wing GP content. This is also the first study documenting changes in epidermal lipid composition resulting from Pseudogymnoascus destructans infection. The reduction in total GP lipid in damaged wing tissue approached significance, with a large effect size, and several

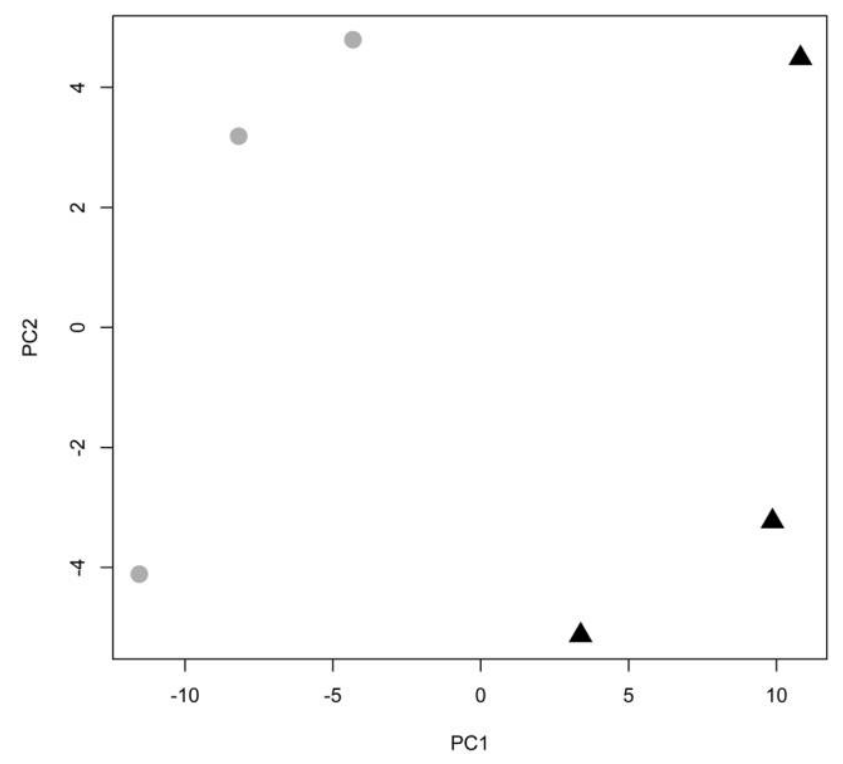

Figure 3. Principle component analysis of complete-presence glycerophospholipid ions profiled in healthy and damaged Myotis lucifugus wing tissue (circles $=$ healthy tissue, triangles $=$ damaged tissue). 
Table 2: Comparison of individual glycerophospholipid ions (nmol amount/mg dry tissue weight) between healthy and necrotic Myotis lucifugus wing tissue

\begin{tabular}{|c|c|c|c|c|c|}
\hline GP & Formula & $\mathrm{M}+\mathrm{H}$ & Mean (healthy) & Mean (damaged) & $P$ \\
\hline $\operatorname{PS}(40: 6)$ & $\mathrm{C}_{46} \mathrm{H}_{78} \mathrm{O}_{10} \mathrm{PN}$ & 836.5442 & $.034 \pm .001$ & $.026 \pm .001$ & .008 \\
\hline $\operatorname{PS}(38: 2)$ & $\mathrm{C}_{44} \mathrm{H}_{82} \mathrm{O}_{10} \mathrm{PN}$ & 816.5755 & $.036 \pm .003$ & $.028 \pm .003$ & .016 \\
\hline $\operatorname{PE}(40: 6)$ & $\mathrm{C}_{45} \mathrm{H}_{78} \mathrm{O}_{8} \mathrm{PN}$ & 792.5543 & $.017 \pm .007$ & $.028 \pm .007$ & .042 \\
\hline $\mathrm{PE}(38: 4)$ & $\mathrm{C}_{43} \mathrm{H}_{78} \mathrm{O}_{8} \mathrm{PN}$ & 768.5543 & $.115 \pm .006$ & $.049 \pm .006$ & .030 \\
\hline $\operatorname{PE}(36: 2)$ & $\mathrm{C}_{41} \mathrm{H}_{78} \mathrm{O}_{8} \mathrm{PN}$ & 744.5543 & $.094 \pm .006$ & $.037 \pm .006$ & .016 \\
\hline $\operatorname{PE}(34: 2)$ & $\mathrm{C}_{39} \mathrm{H}_{74} \mathrm{O}_{8} \mathrm{PN}$ & 716.5230 & $.029 \pm<.001$ & $.007 \pm<.001$ & .002 \\
\hline $\operatorname{PE}(34: 1)$ & $\mathrm{C}_{39} \mathrm{H}_{76} \mathrm{O}_{8} \mathrm{PN}$ & 718.5387 & $.024 \pm .001$ & $.009 \pm .001$ & .020 \\
\hline $\mathrm{PC}(38: 3)$ & $\mathrm{C}_{46} \mathrm{H}_{86} \mathrm{O}_{8} \mathrm{PN}$ & 812.6169 & $.042 \pm .002$ & $.038 \pm .002$ & .036 \\
\hline $\mathrm{PC}(36: 2)$ & $\mathrm{C}_{44} \mathrm{H}_{84} \mathrm{O}_{8} \mathrm{PN}$ & 786.6013 & $.143 \pm .006$ & $.045 \pm .006$ & .005 \\
\hline $\mathrm{PC}(36: 1)$ & $\mathrm{C}_{44} \mathrm{H}_{86} \mathrm{O}_{8} \mathrm{PN}$ & 788.6169 & $.121 \pm .003$ & $.032 \pm .003$ & .004 \\
\hline $\mathrm{PC}(34: 1)$ & $\mathrm{C}_{42} \mathrm{H}_{82} \mathrm{O}_{8} \mathrm{PN}$ & 760.5856 & $.443 \pm .024$ & $.207 \pm .024$ & .028 \\
\hline LPC(18:2) & $\mathrm{C}_{26} \mathrm{H}_{50} \mathrm{O}_{7} \mathrm{PN}$ & 520.3403 & $.036 \pm .001$ & $.008 \pm .001$ & .004 \\
\hline LPC(18:1) & $\mathrm{C}_{26} \mathrm{H}_{52} \mathrm{O}_{7} \mathrm{PN}$ & 522.3560 & $.082 \pm .004$ & $.018 \pm .004$ & .047 \\
\hline LPC(16:0) & $\mathrm{C}_{24} \mathrm{H}_{50} \mathrm{O}_{7} \mathrm{PN}$ & 496.3403 & $.154 \pm .005$ & $.030 \pm .005$ & .032 \\
\hline $\mathrm{PE}(42: 5)$ & $\mathrm{C}_{47} \mathrm{H}_{84} \mathrm{O}_{8} \mathrm{PN}$ & 822.6013 & $.007 \pm .001$ & $\ldots$ & $\cdots$ \\
\hline $\mathrm{PE}(42: 4)$ & $\mathrm{C}_{47} \mathrm{H}_{86} \mathrm{O}_{8} \mathrm{PN}$ & 824.6169 & $.011 \pm .001$ & $\cdots$ & $\ldots$ \\
\hline $\mathrm{PE}(38: 2)$ & $\mathrm{C}_{43} \mathrm{H}_{82} \mathrm{O}_{8} \mathrm{PN}$ & 772.5856 & $.010 \pm .002$ & $\cdots$ & $\cdots$ \\
\hline $\mathrm{PE}(36: 4)$ & $\mathrm{C}_{41} \mathrm{H}_{74} \mathrm{O}_{8} \mathrm{PN}$ & 740.5230 & $.019 \pm .001$ & $\cdots$ & $\cdots$ \\
\hline $\mathrm{PC}(32: 2)$ & $\mathrm{C}_{40} \mathrm{H}_{76} \mathrm{O}_{8} \mathrm{PN}$ & 730.5387 & $.010 \pm<.001$ & $\ldots$ & $\ldots$ \\
\hline LPC(16:1) & $\mathrm{C}_{24} \mathrm{H}_{48} \mathrm{O}_{7} \mathrm{PN}$ & 494.3247 & $.023 \pm .002$ & $\ldots$ & $\cdots$ \\
\hline
\end{tabular}

Note. All data are means \pm SE. Significantly higher means are shown in bold. $n=3$ per treatment. M $+\mathrm{H}=$ hydrogen adduct detected in positive mode. Note that six ions were detected only in healthy tissue. PS, phosphatidylserine; PE, phosphatidylethanolamine; PC, phosphatidylcholine; LPC, lysophosphatidylcholine.

individual GP classes (PC, PE, eGPs, and LGPs) were significantly lower in damaged tissues, resulting in a lower GP:SM ratio. We identified 14 lipid molecules that differed between inoculated and control bats and a further six lipid molecules that were not detected from inoculated bats but present in controls. These differences could indicate candidate lipid biomarkers for $P$. destructans infection, but the results should be interpreted cautiously. The lipids that differed between infected bats and controls belong to four broad GP classes, and it is unlikely that these specific lipids are targeted during fungal infection. Altered GP:SM ratios and lower proportions of unsaturated FAs might not necessarily reflect a localized consequence of fungal infection (such as increased host enzyme activity) but could represent a clinical sign of lipoxidative stress from free radicals during WNS (Pamplona 2008, 2011; reviewed in Yin et al. 2011). Unsaturated membrane GP FAs are sensitive to oxidation due to the presence of a methylene group between FA double bonds and a hypothesized increased radical concentration in the interior organic membrane layer. Our data are consistent with GP and membrane oxidation during fungal infection, which is common in many diseases and aging processes (Negre-Salvayre et al. 2010). Rather than the parent lipids we have analyzed in this study, oxidative lipid products produced in these reactions may serve as highly informative biomarkers (Dalle-Donne et al. 2006) and may have a variety of downstream physiological consequences.

Lipid profiles are unique among tissue types within single species. In bats, wing surface lipid profiles are characterized as being higher in free fatty acids (FFAs) and sterol/wax esters than hair or wing epidermal tissue (Pannkuk et al. 2012). Nine broad lipid classes have been described among 17 mouse tissues and plasma (Jain et al. 2014). PC, which is a major constituent of cellular membranes, is uniformly distributed among tissues. However, the individual PC molecular species may vary, as $\mathrm{PC}(32: 0)$ was higher in brain and lung tissue than epidermal tissue. As lipids are not direct genetic products, a full lipidomic understanding of their occurrence across tissues is complicated. Furthermore, the varied life histories of bat species, hibernation status, and emaciation during $P$. destructans infection may affect lipid profiles. Given the complexity of obtaining a comprehensive lipidome, determining function from altered lipid profiles in a bat $/ P$. destructans system requires further experimentation. Theoretically, epidermal necrosis and cell lysis would contribute to lower wing elasticity and water loss observed during WNS. Also, oxidation products from lysed cellular membranes will have downstream reactions with other molecules.

Few studies have cataloged bat polar lipid profiles, including SM and GP content. Thus, our data provide valuable baseline information on lipid profiles in bats, in general. Comparisons with the limited number of previous studies allow preliminary assessment of tissue and species variation in lipid profiles. We found that SM ( $50 \%)$ is the dominant polar lipid present in Myotis lucifugus epidermal wing tissue. PC (17\%) and PS (12\% of total polar lipid) comprise the dominant GP classes in $M$. lucifugus epidermal wing tissue, with lower amounts of PE, PG, PS, LPC, and ePE. SM FAs from Rousettus aegyptiacus brain and 
spinal cord (primarily 18:0, 24:0/24:1, and >24 C lengths; van der Westhuyzen and Cantrill 1983) are characterized by longer chain lengths compared to M. lucifugus wing tissue SM FAs we describe (predominantly 16:0, with lower amounts of 18:0, $22: 1,22: 0,24: 1$, and $24: 0)$. The GP fraction in our study was similar to that observed for Lasiurus borealis hair sebaceous lipid (Pannkuk et al. 2014c), but there were minor differences. While PC $(\sim 70 \%)$ and PI $(\sim 15 \%)$ were dominant GP classes in $L$. borealis hair (Pannkuk et al. 2014c), here we found that PC $(\sim 30 \%)$ and PS $(\sim 21 \%)$ were dominant in wing tissue. LPCs were similar between $L$. borealis hair and $M$. lucifugus wing tissue, with 16:0, 18:0, and 18:1 dominant FAs. PCs and PGs were dominantly $32-36 \mathrm{C}$, with $\mathrm{PC}(34: 1)$ and $\mathrm{PG}(34: 1)$ in the highest concentration. PS and PE were primarily $36 \mathrm{C}$ in $L$. borealis hair (36:1 highest PS; 36:1, 36:2, and 34:1 highest PEs); however, M. lucifugus wing tissue has higher proportions of 38 and 40 C PS lipids, possibly due to greater 20 C FA constituents. Future studies adding to the number of species and tissues examined will facilitate comparisons and may identify ecological or physiological factors that lead to similarities and differences in polar lipid profiles. However, altered lipid profiles due to hibernation status must also be addressed in future studies (Frank et al. 2012).

One current challenge for determining potential lipid biomarkers in WNS is isolating/determining the lipid source. Lipids in a bat $/ P$. destructans system can originate from fungal or mammalian tissues. Pseudogymnoascus destructans lipids are characterized as sterols (presumably, a majority of ergosterol), FFAs, and triacylglycerides (TAGs; Pannkuk et al. 2014a). The fungal FFAs and glycerolipids are partially differentiated from mammalian sources by higher proportions of polyunsaturated FAs (i.e., 18:2 and 18:3) compared to mammalian glycerolipids, which are typically dominated by saturated or monounsaturated FAs (i.e., 16:0 and 18:1). Additionally, plants and fungi produce ceramide phosphorylinositol instead of SM (the most abundant animal SP; Gault et al. 2010). The reduced GP:SM ratio, absence of six GP molecules in inoculated bats, and prevalence of unsaturated and monounsaturated FAs (figs. S3, S8) suggest that differences we observed are not the result of fungal lipids but rather reflect changes in the host lipid profile following infection. Furthermore, the use of whole-tissue biomass rather than isolatingsurface lipid reduces the influence of fungal lipids on the observed profiles.

Despite many recent advances in the study of WNS, many of the mechanisms underlying the disease remain essentially a black box. Warnecke et al. (2013) proposed a mechanistic model of WNS pathophysiology, but many of its components remain theoretical and untested (Warnecke et al. 2013). Lipid analyses, such as those presented here, can help improve understanding of the mechanistic interactions between host and pathogen and provide critical information about the physiological consequences of infection. We suggest that future studies compare oxidative lipid products for possible biomarkers of $P$. destructans infection (rather than parent lipids; DalleDonne et al. 2006); determine how lipid profiles of laboratory- infected bats compare to natural infections in the environment; determine how lipid content changes during the healing process; and develop further methodology for separating cellular, fungal, and secreted lipid fractions. Identification of biomarkers in hostpathogen systems may lead to development of novel therapeutic and diagnostic technologies.

\section{Acknowledgments}

This project was funded by an Arkansas State Wildlife Grant, the National Speleological Society, the Graduate Program of Environmental Science at Arkansas State University (ASU), the US Fish and Wildlife Service, a Government of Canada Postdoctoral Fellowship (PDRF), the Natural Sciences and Engineering Research Council (NSERC; Canada), the German Academic Exchange Service (DAAD), and the Center for North American Bat Research and Conservation at Indiana State University. Laboratory assistance was provided by K. Arter and H. Southe (ASU). Trent Bollinger, Vikram Misra, and the animal care staff of the Western College of Veterinary Medicine (WCVM) provided outstanding support during the inoculation experiment, and the necropsy team in the WCVM Veterinary Pathology department provided UV photos. Lipid profile data were acquired at Kansas Lipidomics Research Center (KLRC). Instrument acquisition and method development at KLRC was supported by NSF grants MCB 0455318, MCB 0920663, and DBI 0521587; Kansas Networks of Biomedical Research Excellence (INBRE; National Institutes of Health grant P20 RR16475 from the INBRE program of the National Center for Research Resources); National Science Foundation Experimental Program to Stimulate Competitive Research grant EPS0236913; Kansas Technology Enterprise Corporation; and Kansas State University.

\section{Literature Cited}

Aktas M., M. Wessel, S. Hacker, S. Klüsener, J. Gleichenhagen, and F. Narberhaus. 2010. Phosphatidylcholine biosynthesis and its significance in bacteria interacting with eukaryotic cells. Eur I Cell Biol 89:888-894.

Blehert D.S., A.C. Hicks, M. Behr, C.U. Meteyer, B.M. Berlowski-Zier, E.L. Buckles, J.T.H. Coleman, et al. 2009. Bat white-nose syndrome: an emerging fungal pathogen? Science 323:227.

Brock M. 2009. Fungal metabolism in host niches. Curr Opin Microbiol 12:371-376.

Brown D.A. and E. London. 1998. Structure and origin of ordered lipid domains in biological membranes. L Membr Biol 164:103-114.

Cajka T. and O. Fiehn. 2014. Comprehensive analysis of lipids in biological systems by liquid chromatography-mass spectrometry. Trends Anal Chem 61:192-206.

Comerci D.J., S. Altabe, D. de Mendoza, and R.A. Ugalde. 2006. Brucella abortus synthesizes phosphatidylcholine from choline provided by the host. L Bacteriol 188:1929-1934. 
Cryan P.M., C.U. Meteyer, D.S. Blehert, J.M. Lorch, D.M. Reeder, G.G. Turner, J. Webb, et al. 2013. Electrolyte depletion in white-nose syndrome bats. LWildl Dis 49:398402.

Cryan P.M., C.U. Meteyer, J.G. Boyles, and D.S. Blehert. 2010. Wing pathology of white-nose syndrome in bats suggests life-threatening disruption of physiology. BMC Biol 8:135.

Dalle-Donne I., R. Rossi, R. Colombo, D. Giustarini, and A. Milzani. 2006. Biomarkers of oxidative damage in human disease. Clin Chem 52:601-623.

Elias P.M. 2006. Defensive functions of the stratum corneum: integrative aspects. Pp. 5-14 in P.M. Elias and K.R. Feingold, eds. Skin barrier. Taylor \& Francis, New York.

Fahy E., S. Subramaniam, H.A. Brown, C.K. Glass, A.H. Merrill, R.C. Murphy, C.R.H. Raetz, et al. 2005. A comprehensive classification system for lipids. L Lipid Res 46:839.

Fahy E., S. Subramaniam, R.C. Murphy, M. Nishijima, C.R.H. Raetz, T. Shimizu, F. Spener, G. van Meer, M.J.O. Wakelam, and E.A. Dennis. 2009. Update of the LIPID MAPS comprehensive classification system for lipids. J Lipid Res 50 (suppl.):S9-S14.

Frank C.L., P.M. Diaz, and T.H. Kunz. 2012. The relationship between white nose syndrome and dietary PUFA levels in bats. Pp. 271-279 in T. Ruf, C. Bieber, W. Arnold, and E. Millesi, eds. Living in a seasonal world: thermoregulatory and metabolic adaptations. Springer, Berlin.

Frick W.F., J.F. Pollock, A.C. Hicks, K.E. Langwig, D.S. Reynolds, G.G. Turner, C.M. Butckoski, and T.H. Kunz. 2010. An emerging disease causes regional population collapse of a common North American bat species. Science 329:679-682.

Gault C.R., L.M. Obeid, and Y.A. Hannun. 2010. An overview of sphingolipid metabolism: from synthesis to breakdown. Adv Exp Med Biol 688:1-23.

Greenberg J.T. and N. Yao. 2004. The role and regulation of programmed cell death in plant-pathogen interactions. Cell Microbiol 6:201-211.

Hannun Y.A. and L.M. Obeid. 2011. Many ceramides. I Biol Chem 286:27855-27862.

Jain M., S. Ngoy, S.A. Sheth, R.A. Swanson, E.P. Rhee, R. Liao, C.B. Clish, V.K. Mootha, and R. Nilsson. 2014. A systematic survey of lipids across mouse tissues. Am I Physiol Endocrinol Metab 306:E854-E868.

Lang C.J., A.D. Postle, S. Orgeig, F. Possmayer, W. Bernhard, A.K. Panda, K.D. Jürgens, W.K. Milsom, K. Nag, and C.B. Daniels. 2005. Dipalmitoylphosphatidylcholine is not the major surfactant GPs species in all mammals. Am I Physiol 289: R1426-R1439.

Law S., P.W. Wertz, D.C. Swartzendruber, and C.A. Squier. 1995. Regional variation in content, composition, and organization of porcine epithelial barrier lipids revealed by thin layer chromatography and transmission electron microscopy. Arch Oral Biol 40:1085-1091.

Lorch J.M., C.U. Meteyer, M.J. Behr, J.G. Boyles, P.M. Cryan, A.C. Hicks, A.E. Ballmann, et al. 2011. Experimental infection of bats with Geomyces destructans causes white-nose syndrome. Nature 480:376-378.
Mak T.D., E.C. Laiakis, M. Goudarzi, and A.J. Fornace Jr. 2014. MetaboLyzer: a novel statistical workflow for analyzing postprocessed LC-MS metabolomics data. Anal Chem 86:506-513.

Mapstone M., A.K. Cheema, M.S. Fiandaca, X. Zhong, T.R. Mhyre, L.H. MacArthur, W.J. Hall, et al. 2014. Plasma phospholipids identify antecedent memory impairment in older adults. Nat Med 20:415-420.

McGuire L.P., M.B. Fenton, and C.G. Guglielmo. 2013. Phenotypic flexibility in migrating bats: seasonal variation in body composition, organ sizes and fatty acid profiles. LExp Biol 216:800-808.

Melville D.F., S.D. Johnston, and R.R. Miller Jr. 2012. Flyingfox (Pteropus spp.) sperm membrane fatty acid composition, its relationship to cold shock injury and implications for cryopreservation success. Cryobiology 65:224229.

Meteyer C.U., E.L. Buckles, D.S. Blehert, A.C. Hicks, D.E. Green, V. Shearn-Bochsler, N.J. Thomas, A. Gargas, and M.J. Behr. 2009. Histopathologic criteria to confirm whitenose syndrome in bats. I Vet Diagn Invest 21:411-414.

Muller L.K., J.M. Lorch, D.L. Lindner, M. O’Connor, A. Gargas, and D.S. Blehert. 2013. Bat-white-nose syndrome: a real-time TaqMan polymerase reaction test targeting the intergenic spacer region of Geomyces destructans. Mvcologia 105:253-259.

Nagan N. and R.A. Zoeller. 2001. Plasmalogens: biosynthesis and functions. Prog Lipid Res 40:199-229.

Negre-Salvayre A., N. Auge, V. Ayala, H. Basaga, J. Boada, R. Brenke, S. Chapple, et al. 2010. Pathological aspects of lipid peroxidation. Free Radic Res 44:1125-1171.

Nuzzo R. 2014. Statistical errors: $P$ values, the "gold standard" of statistical validity, are not as reliable as many scientists assume. Nature 506:150-152.

Pamplona R. 2008. Membrane phospholipids, lipoxidative damage and molecular integrity: a causal role in aging and longevity. Biochim Biophys Acta 1777:1249-1262.

. 2011. Advanced lipoxidation end-products. ChemicoBiol Interact 192:14-20.

Pannkuk E.L., H.B. Blair, A.E. Fischer, C.L. Gerdes, D.F. Gilmore, B.J. Savary, and T.S. Risch. 2014a. Triacylglyceride composition and fatty acyl saturation profile of a psychrophilic and psychrotolerant fungal species grown at different temperatures. Fungal Biol 118:792-799.

Pannkuk E.L., N.W. Fuller, P.R. Moore, D.F. Gilmore, B.J. Savary, and T.S. Risch. 2014b. Fatty acid methyl ester profiles of bat wing surface lipids. Lipids 49:1143-1150.

Pannkuk E.L., D.F. Gilmore, B.J. Savary, and T.S. Risch. 2012. Triacylglycerid (TAG) profiles of integumentary lipids isolated from three bat species determined by matrix-assisted laser desorption-ionization time-of-flight mass spectrometry (MALDI-TOF MS). Can I Zool 90:1117-1127.

Pannkuk E.L., L.P. McGuire, D.F. Gilmore, B.J. Savary, and T.S. Risch. 2014c. Glycerophospholipid analysis of eastern red bat (Lasiurus borealis) hair by electrospray ionization tandem mass spectrometry. LChem Ecol 40:227-235. 
Pannkuk E.L., T.S. Risch, and B.J. Savary. 2013. Profiling the triacylglyceride contents in bat integumentary lipids by preparative thin layer chromatography and MALDI-TOF mass spectrometry. J Vis Exp 50757. http://dx.doi.org/10 $.3791 / 50757$.

Reynolds T.B. 2009. Strategies for acquiring the phospholipid metabolite inositol in pathogenic bacteria, fungi and protozoa: making it and taking it. Microbiology 155:1386-1396.

Silvius J.R. 1993. Structure and nomenclature. Pp. 1-22 in G. Cevc, ed. Phospholipids handbook. Dekker, New York.

Slocombe N.C., J.R. Codd, P.G. Wood, S. Orgeig, and C.B. Daniels. 2000. The effect of alterations in activity and body temperature on the pulmonary surfactant system in the lesser long-eared bat (Nyctophilus geoffroyi). L Exp Biol 203: 2429-2435.

Turner G.G., C.U. Meteyer, H. Barton, J.F. Gumbs, D.M. Reeder, B. Overton, H. Bandouchova, et al. 2014. Nonlethal screening of bat-wing skin with the use of ultraviolet fluorescence to detect lesions indicative of white-nose syndrome. LWildl Dis 50:566-573.

van der Meer-Janssen Y.P.M., J. van Galen, J.J. Batenburg, and J. Bernd Helms. 2010. Lipids in host-pathogen interactions: pathogens exploit the complexity of the host cell lipidome. Prog Lipid Res 49:1-26.

van der Westhuyzen J. and R.C. Cantrill. 1983. Lipid composition and sphingolipid fatty acids of myelin in fruit bat brain. Neurochem Int 5:365-368.
Vihervaara T., M. Suoniemi, and R. Laaksonen. 2014. Lipidomics in drug discovery. Drug Discov Todav 19:164170.

Wanjie S.W., R. Welti, R.A. Moreau, and K.D. Chapman. 2005. Identification and quantification of glycerolipids in cotton fibers: reconciliation with metabolic pathway predictions from DNA databases. Lipids 40:773-785.

Warnecke L., J.M. Turner, T.K. Bollinger, J.M. Lorch, V. Misra, P.M. Cryan, G. Wibbelt, D.S. Blehert, and C.K.R. Willis. 2012. Inoculation of bats with European Geomyces destructans supports the novel pathogen hypothesis for the origin of white-nose syndrome. Proc Natl Acad Sci USA 109:6999-7003.

Warnecke L., J.M. Turner, T.K. Bollinger, V. Misra, P.M. Cryan, D.S. Blehert, G. Wibbelt, and C.K.R. Willis. 2013. Pathophysiology of white-nose syndrome in bats: a mechanistic model linking wing damage to mortality. Biol Lett 9: 20130177.

Willis C.K.R., A.K. Menzies, J.G. Boyles, and M.S. Wojciechowski. 2011. Evaporative water loss is a plausible explanation for mortality of bats from white-nose syndrome. Integr Comp Biol 51:364-373.

Yike I. 2011. Fungal proteases and their pathophysiological effects. Mycopathologia 171:1-25.

Yin $\mathrm{H}$., L. Xu, and N.A. Porter. 2011. Free radical lipid peroxidation: mechanisms and analysis. Chem Rev 111:59445972. 